\title{
PELATIHAN MEMBUAT DAN MENGELOLA WEBSITE SEKOLAH
}

\author{
Nurul Izzah ${ }^{1}$ \\ ${ }^{1}$ Institut Agama Islam Negeri Padangsidimpuan \\ Email : iniizzah08@gmail.com
}

\begin{abstract}
ABSTRAK
Website dalam perkembangnnya telah merambah ke berbagai sisi kehidupan termasuk dunia pendidikan. Website sekolah merupakan media informasi yang dapat dimanfaatkan sekolah secara efektif dan efisien dalam penyampaian informasi-informasi yang berhubungan dengan sekolah. Kegiatan dilakukan secara tatap muka selama satu hari dengan tetap menerapkan protokol kesehatan dalam pencegahan Covid-19. Metode pelatihan dilakukan dengan beberapa tahapan yang dimulai dari perencanaan, pelaksanaan dan evaluasi. Pelatihan lebih menitikberatkan pada kegiatan praktek dibandingkan dengan penjabaran materi. Hasil kegiatan pelatihan menunjukkan bahwa peserta pelatihan memiliki pemahaman yang meningkat terkait manfaat website sekolah sebagai sarana atau media informasi sekolah. Kemampuan peserta pelatihan terkait cara membuat dan mengelola website sekolah juga mengalami peningkatan. Hal ini ditunjukkan dari website sekolah yang dapat diakses dengan tampilan beranda website yang menarik dan informatif.
\end{abstract}

Kata Kunci : Informasi, Pelatihan, Sekolah, Website. 


\section{PENDAHULUAN}

Teknologi dan informasi yang berkembang sangat cepat membuat cara pandang masyarakat terhadap teknologi informasi. Website adalah sarana yang telah banyak digunakan yang fungsinya untuk memperkenalkan dan sebagai sumber informasi yang diperlukan (Akbar \& Tjendrowaseno, 2015). Website dapat juga diartikan sebagai kumpulan halaman yang dapat menampilkan berbagai informasi dalam bentuk teks, suara, gambar, animasi atau gabungan dari beberapa bentuk atau semuanya (Nurmi, 2017) dengan kata lain bahwa website sebagai alat yang dapat digunakan untuk menampilkan diri, perusahaann, sekolah atau organisasi di internet (Harminingtyas, 2014). Website memiliki banyak fungsi seperti sebagai media informasi dan komunikasi, media pemasaran atau promosi, dan media pendidikan (Zaki, 2009).

Perkembangan teknologi telah telah mendorong munculnya berbagai aktivitas yang berlandaskan pada teknologi informasi, seperti e-commerce, e-education dan lain sebagainya. (Wijaya \& Ferdinandus, 2020). Pada dunia Pendidikan, saat ini banyak sekolah yang menyediakan teknologi informasi di sekolah-sekolah. Hal ini dilakukan untuk memberikan kemudahan untuk mengakses informasi. Banyak sekolah yang telah lama memanfaatkan teknologi informasi dalam berbagai kegiatan sekolah seperti mulai dari penerimaan perserta didik baru sampai dengan berbagai informasi-informasi terupdate terkait sekolah.

Pandemi Covid-19 yang melanda dunia telah mempengaruhi berbagai sisi kehidupan manusia termasuk dunia pendidikan dan lain sebagainya. Covid-19 yang merebak dengan cepat membuat pemerintah mengambil kebijakan dengan membatasi akses keluar masuk beberapa wilayah. Covid-19 telah menjadikan berbagai aktivitas masyarakat terhambat (Nadhira Salsabila, 2020). Kebijakan pemerintah untuk membatasi aktivitas masyarakat merupakan langkah strategis guna memberikan perlindungan terhadap masyarakat. Pembatasan ditekankan kepada kegiatan-kegiatan yang sifatnya mengumpulkan banyak orang. Sehingga muncul himbauan agar bekerja, belajar dan beribadah di rumah (Thorik, 2020).

Sejak September 2020, Kabupaten Mandailing Natal Provinsi Sumatera Utara berubah status dari zona orange menjadi zona merah Covid-19 (Fanani, 2020). Perubahan status ini membuat pemerintah Kabupaten Mandiling Natal membatalkan rencana kegiatan belajar tatap muka. Sebelumnya pemerintah telah merencanakan untuk melangsungkan kegaitan belajar tatap muka pada 1 September 2020 (Sandy Waradewa, 2020). Kondisi ini membuat masyarakat 
di Kabupaten Mandailing Natal harus membatasi berbagai aktivitas yang biasa dilakukan sehari-hari.

Mendikbud, Nadiem Makarim menyatakan bahwa pedoman kebijakan pendidikan selama pandemi Covid-19 yaitu dengan memprioritaskan kesehatan dan keselamatan semua peserta didik, pendidik, tenaga kependidikan, keluarga dan masyarakat. Sekolah yang ditutup selama pandemi Covid-19 bukan berarti kegiatan pembelajaran juga ikut berhenti. UNICEF dan Kementerian Pendidikan dan Kebudayaan telah membuat materi pembelajaran secara Offline dan merumuskan pedoman untuk mencegah dan merespon Covid-19 di sektor pendidikan (Sikirit, 2020).

Website sekolah bisa menjadi salah satu wadah yang sangat memudahkan pihak sekolah selama pandemi Covid-19 untuk menyampaikan berbagai informasi kepada publik dengan efiektif dan efisien. Taman Pendidikan Al-Qur'an (TPA) Al-Azhar merupakan salah satu sekolah yang berada di Panyabungan Kabupaten Mandailing Natal. TPA Al-Azhar belum memiliki website sekolah sehingga berbagai informasi dan perkembangan aktivitas sekolah disampaikan secara sederhana yaitu dengan menggunakan papan pengumuman atau melalui pengumuman lisan ataupun tulisan yang biasanya dibagikan kepada peserta didik. Penyampaian informasi seperti ini selama pandemi Covid-19 dirasa belum efektif dan efisien. TPA Al-Azhar tidak memiliki website dikarenakan pihak sekolah merasa cara penyampaian informasi yang dilakukan selama ini dinilai masih efektif. Kondisi ini juga disebabkan oleh tenaga pendidik yang ada memiliki pengetahuan yang minim terkait cara membuat dan mengelola website sekolah.

Berdasarkan latar belakang tersebut, perlu dilakukan pelatihan membuat dan mengelola website sekolah bagi tenaga pendidik di sekolah TPA Al-Azhar. Kegiatan pelatihan yang dilakukan diharapkan meningkatkan kemampuan tenaga pendidik sekolah TPA Al-Azhar dalam membuat dan mengelola website sekolah.

\section{METODE}

Pelatihan membuat dan mengelola website sekolah ini diikuti sebanyak dua tenaga pendidik yang mengajar di TPA Al-Azhar. Pelatihan dilaksanakan secara tatap muka di ruang kelas dengan tetap memenuhi protokol kesehatan. Pelatihan diawali dengan penjelasan 
pentingnya website sekolah untuk memudahkan sekolah dalam menyampaikan berbagai informasi terkait TPA Al-Azhar kepada wali murid dan masyarakat. Kemudian dilanjutkan dengan materi membuat website, membuat website dengan menggunakan domain gratis mysch.id dan dilanjutkan dengan pengelolaan website yang telah dibuat.

Website yang telah dibuat hanya memuat nama sekolah, nama kepala sekolah dan alamat sekolah. Menu lain yang diperlukan harus ditambahkan oleh admin sekolah melalui link admin yang telah dikirimkan ke email admin sekolah. Website tersebut selanjutnya dikelola oleh admin yang juga merupakan tenaga pendidik sekolah TPA Al-Azhar. Pengelolaan website dimulai dengan mengupload logo sekolah dan dilanjutkan dengan membuat sambutan singkat dari kepala sekolah dan lainnya. Langkah-langkah pelatihan membuat dan mengelola website sekolah TPA Al-Azhar sebagai berikut :

1. Perencanaan

Perencanaan yang dilakukan berkaitan dengan kebutuhan yang diperlukan oleh TPAAl-Azhar untuk memudahkan penyampaian informasi. Pertama sekali ditentukan domain website yang akan digunakan, kemudian menentukan jadwal pelatihan dan merumuskan materi yang akan disampaikan pada pelatihan.

2. Pelaksanaan

Pelatihan dilakukan dalam 1 hari dan langsung dipandu oleh Nurul Izzah, dosen Fakultas Ekonomi dan Bisnis Islam IAIN Padangsidimpuan. Membuat website dan memahami cara mengelola website sekolah menjadi tujuan penting dalam pelatihan ini. Materi pelatihan disajikan sebagai berikut.

Tabel 1. Materi Pelatihan Membuat dan Mengelola Website Sekolah

\begin{tabular}{|c|c|c|c|}
\hline Sesi ke- & Materi & Metode & Keterangan \\
\hline I & $\begin{array}{l}\text { 1. Pentingnya Website Sekolah. } \\
\text { 2. Tujuan dan Manfaat Website } \\
\text { Sekolah. } \\
\text { 3. Pembuatan Website Sekolah } \\
\text { dengan domain mysch.id }\end{array}$ & $\begin{array}{l}\text { Ceramah, tanya } \\
\text { jawab dan pratek }\end{array}$ & $\begin{array}{l}40 \% \text { teori dan } \\
60 \% \text { Praktek }\end{array}$ \\
\hline II & $\begin{array}{l}\text { 1. Praktek Pembuatan Website } \\
\text { sekolah dengan domain } \\
\text { mysch.id } \\
\text { 2. Praktek Pengelolaan Website } \\
\text { Sekolah. }\end{array}$ & $\begin{array}{l}\text { Praktek dan } \\
\text { Pendampingan }\end{array}$ & $100 \%$ Praktek \\
\hline
\end{tabular}




\section{Evaluasi}

Evaluasi dilakukan terhadap guru sekolah TPA Al-Azhar yang mengikuti pelatihan. Sebelum pelatihan dimulai pretest diberikan kepada peserta untuk mengetahui pemahaman terhadap materi pelatihan. Setelah pelatihan selesai, peserta diberikan postest untuk mengetahui kemajuan pemahaman dan pengetahuan peserta pelatihan terhadap materi pelatihan pembuatan dan pengelolaan website sekolah yang telah diberikan.

\section{HASIL DAN PEMBAHASAN}

Kegiatan pelatihan membuat dan mengelola website sekolah ini dilaksanakan secara tatap muka dengan tetap mematuhi protokol kesehatan. Teknologi informasi telah berkembang dengan sangat pesat. Pada masa pandemi Covid-19 saat ini, teknologi memiliki kedudukan penting sebagai media informasi untuk tetap dapat melakukan berbagai kegiatan yang memungkinkan untuk dilakukan secara tatap muka (Komalasari, 2020). Teknologi informasi telah terbukti meringankan dan membantu berbagai kegiatan penggunanya. Manfaat tersebut telah banyak dinikmati oleh masyarakat (Rahadi, 2007).

Kegiatan pelatihan yang dilakukan terdiri dari dua sesi. Sesi pertama terkait materi tentang pentingnya memiliki website sekolah dan cara membuat website sekolah. Penyampaian materi terkait tujuan, manfaat dan cara membuat website sekolah disajikan pada Gambar 1. berikut.

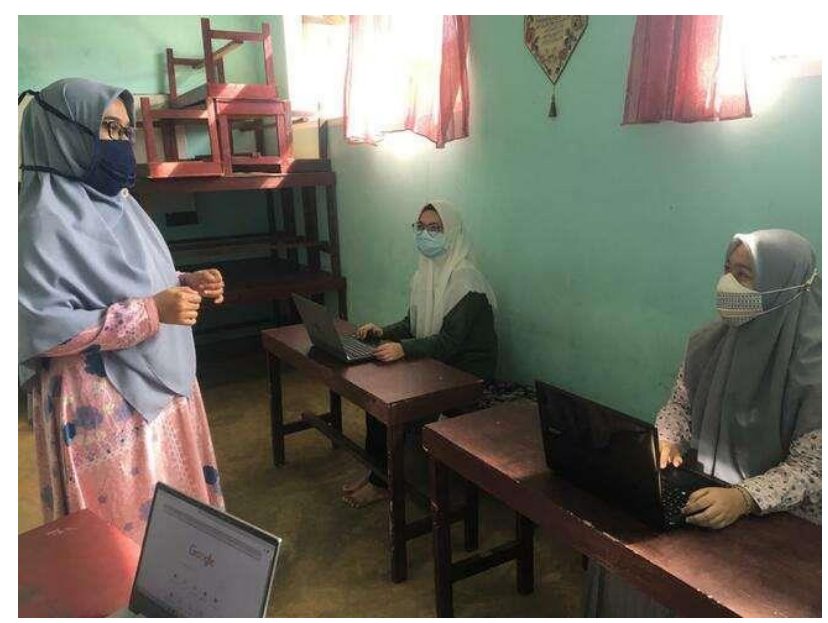

Gambar 1. Penyampaian Materi Pelatihan 
Sesi kedua dilanjutkan dengan praktek membuat dan mengelola website. Website sekolah yang telah dibuat menggunakan domain mysch.id. Mysch.id adalah situs yang menfasilitasi layanan untuk membuat website sekolah dengan menggunakan domain tidak berbayar atau gratis. Mysch.id telah menyediakan tema desain sehingga membuat website dengan domain mysch.id tidak memerlukan keahlian dibidang web desain dan programming (mysch.id, 2020). Website sekolah yang dibuat dengan domain mysch.id ditampilkan pada Gambar 2 berikut.

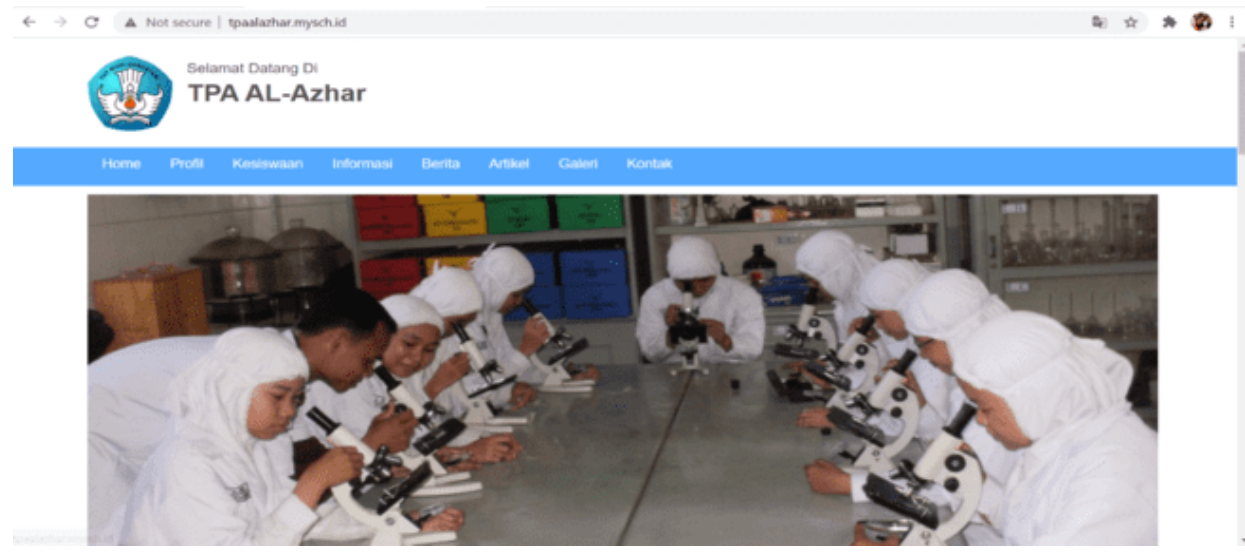

Gambar 2. Tampilan Beranda Website Sekolah yang belum dikelola

Selanjutnya pada sesi kedua materi yang disampaikan terkait bagaimana cara mengelola website sekolah. Sesi kedua dilakukan dengan praktek secara langsung setelah website sekolah dibuat dengan domain mysch.id. hal pertama yang dilakukan yaitu mengupload logo sekolah pada tampilan beranda website sekolah dan dilanjutkan dengan membuat sambutan dari kepala sekolah. Tampilan website yang telah memuat logo sekolah dan kata sambutan kepala sekolah disajikan sebagai berikut.

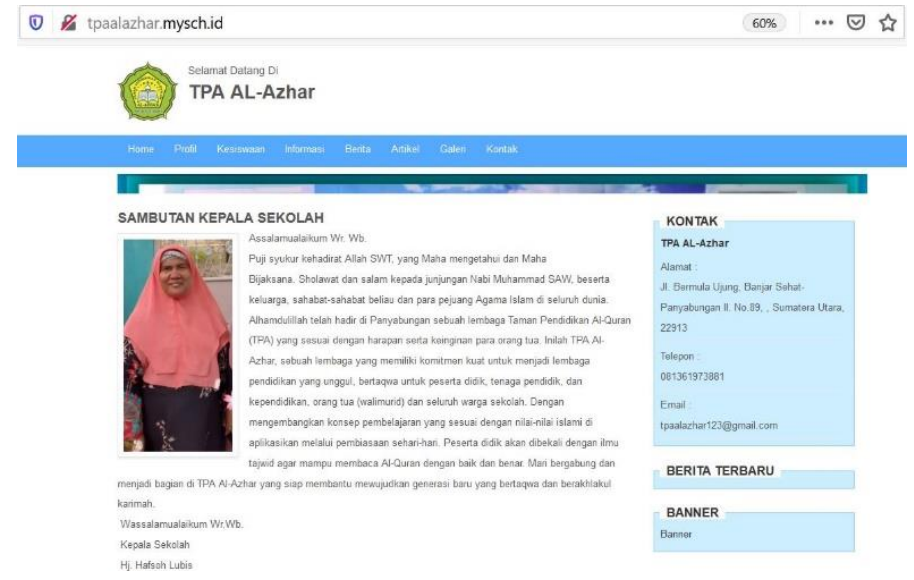


Gambar 3. Logo dan Kata Sambutan Pada Website Sekolah

Website sekolah yang telah memuat logo sekolah dan kata sambutan kepala sekolah selanjutnya di tambahkan foto-foto aktivitas sekolah dalam galery foto website. Pada tahap ini, hanya ada 1 foto yang ditambahkan karena tenaga pendidik masih harus mengumpulkan dan mengelompokkan foto-foto sesuai dengan kegiatannya. Foto yang telah tersimpan di website yaitu foto wisuda tahun 2020. Tampilan website sekolah TPA Al-Azhar yang telah memuat foto disajikan sebagai berikut.

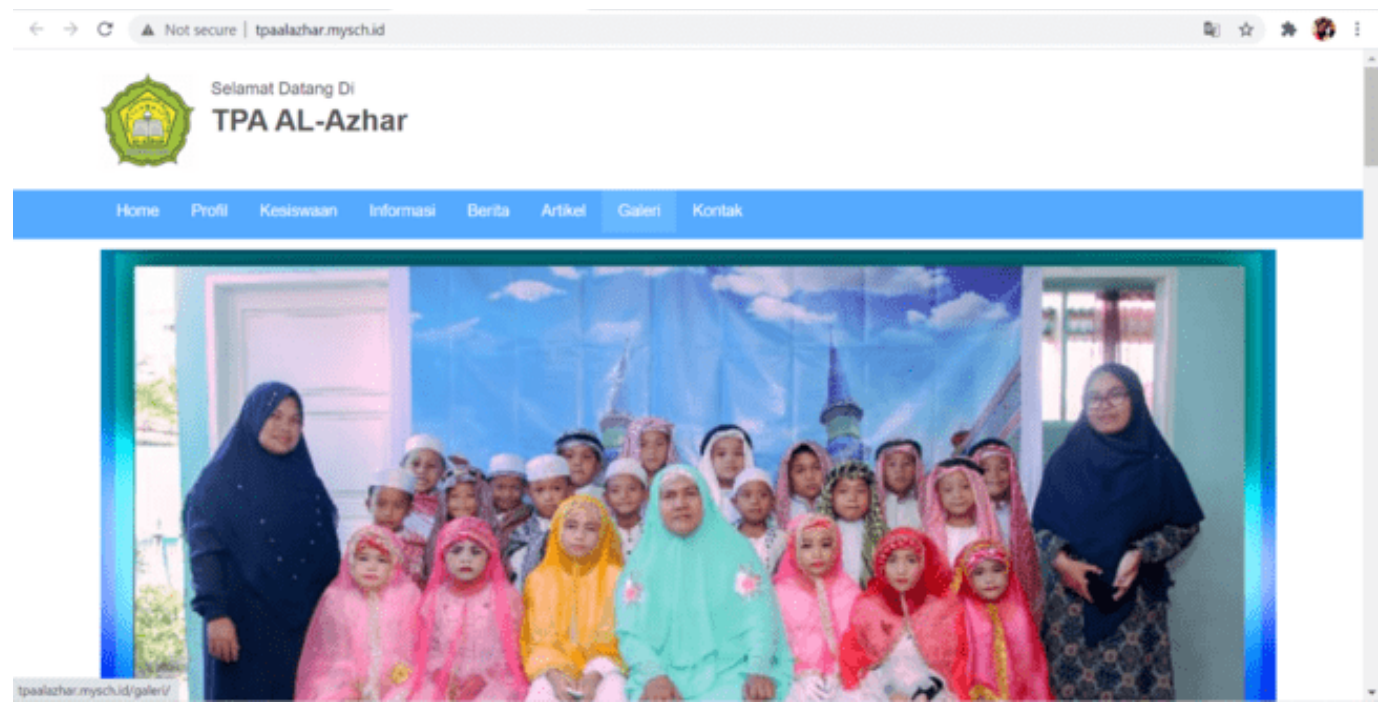

Gambar 4. Foto Wisuda Pada Website Sekolah

Tahap selanjutnya dengan memilih menu-menu pada website sekolah yang tetap akan digunakan dan memilih menu-menu yang akan dihapus dari website. Cara mengubah menu dilakukan melalui pengaturan halaman dengan menekan tombol menu. Pada tabel menu website, pengaturan menu yang dapat dilakukan diantaranya menambah, mengubah, menghapus isi menu dan menyembunyikan, mengatur urutan dan membuat sub menu. Peserta pelatihan dipandu untuk menambah dan menghapus menu dalam website. Menu-menu yang dipilih untuk tetap dipertahankan ada di website disesuaikan dengan kebutuhan sekolah.

Pada sesi terakhir ini dapat dilihat bahwa pemahaman peserta pelatihan dalam membuat dan mengelola website telah mengalami peningkatan. Hal ini sesuai dengan hasil pretest dan postest yang diberikan kepada peserta pelatihan. Hasil pretest dan postest peserta pelatihan disajikan sebagai berikut. 


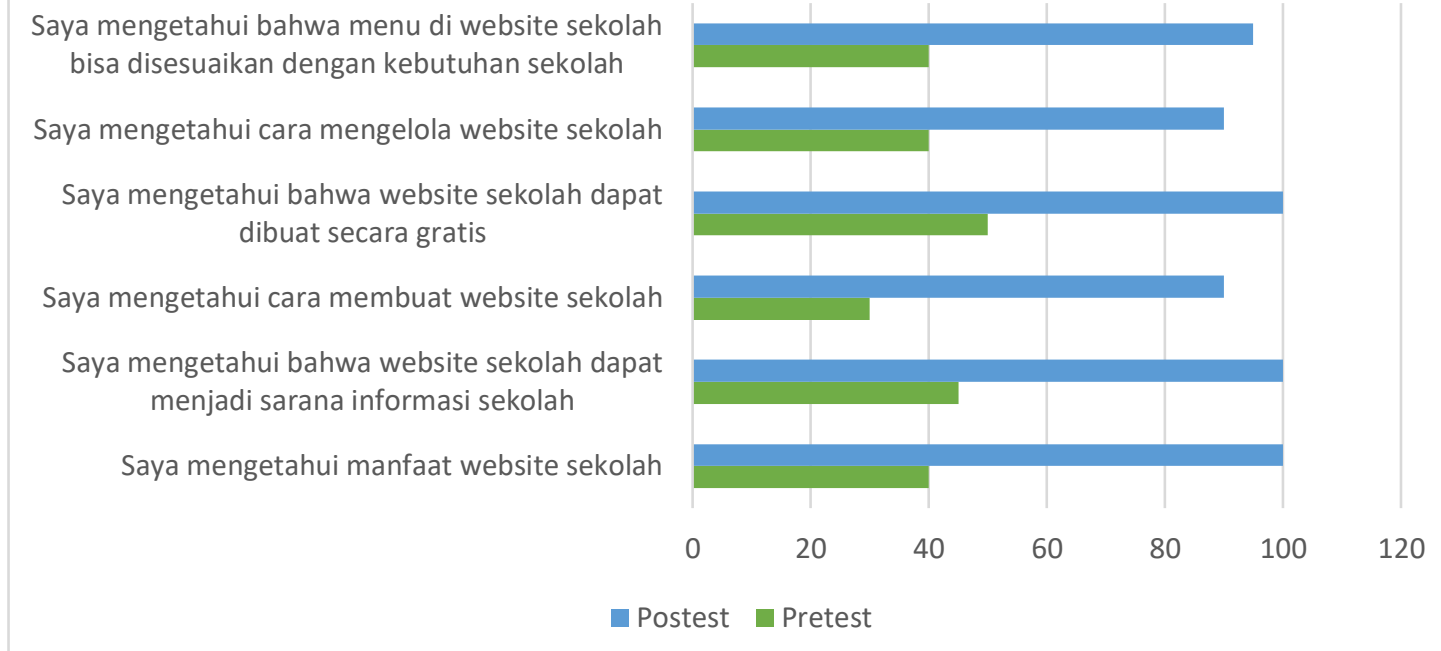

Gambar 5. Hasil Pretest dan Postest

Gambar 5 diatas menunjukkan bahwa tenaga pendidik telah mengetahui manfaat pentingnya website sekolah. Selain itu, tenaga pendidik juga telah mampu membuat dan mengelola website sekolah. Internet sebagai media informasi yang semakin mendunia kini telah menjadi suatu kebutuhan (Marlena \& Sasongko, 2012). Website sekolah TPA AL-Azhar diharapkan dapat dijadikan sebagai sarana informasi sekolah yang efektif dan efisien selama pandemi Covid-19 dan dapat terus dimanfaatkan setelah pandemi berakhir nantinya. Karena pada dasarnya website sekolah bertujuan untuk memberikan berbagai informasi yang berkaitan dengan sekolah secara efektif dan efisien yang dapat diakses dimana saja, kapan saja dan oleh siapa saja (Utomo \& Bakara, 2013). Website sekolah tidak sekedar menjadi media informasi tetapi juga sebagai sarana promosi yang menjangkau lebih luas (Anwar et al., 2017) dan menunjukkan perkembangan profesionalisme sekolah (Khusnia \& Riasti, 2013). Selian itu, website sekolah juga dapat dijadikan sebagai media pendukung kegiatan humas sekolah untuk menunjukkan karakteristik sekolah dengan membangun imagepostif untuk memberikan kesan yang baik kepada masyarakat (Utari, 2013).

Hasil postest juga menunjukkan bahwa tenaga pendidik TP Al-Azhar juga telah mampu mengelola website sekolah. Berbagai menu sekolah TPA AL-Azhar telah disesuaikan dengan kebutuhan sekolah. Website sekolah telah memuat logo sekolah, sambutan dari kepala sekolah dan alamat sekolah pada beranda website. Tenaga pendidik dalam mengelola website sekolah harus mempertimbangkan tata letak dan warna menu yang akan dtambahkan dalam website 
agar tampilan website lebih menarik. Tampilan website yang berkualitas dapat dinilai dari sisi kualitas tampilan, bahasa dan akses. Hal ini dapat dilihat dari informasi yang mudah mengerti, menggunakan bahasa yang dinamis, bervariasi dan tidak membosankan. Tampilan website yang berkualitas diharapkan mampu memberikan kepuasan kepada pengguna website (Sumartono et al., 2020).

\section{KESIMPULAN}

Kegiatan pengabdian kepada masyarakat ini telah meningkatkan pemahaman dan kemampuan tenaga pendidik sekolah TPA AL-Azhar dalam membuat dan mengelola website sekolah. Kemampuan tenaga pendidik peserta pelatihan telah mencapai harapan dan tujuan dari kegiatan ini. Tujuan pelatihan yang telah tercapai ini dapat dilihat dari hasil postest yang menyatakan bahwa tingkat pemahaman dan kemampuan peserta pelatihan terkait cara membuat dan mengelola website sekolah mengalami peningkatan. Tenaga pendidik yang mengelola website sekolah sebaiknya selalu mengikuti perkembangan teknologi komunikasi digital agar website sebagai media informasi sekolah dapat dimanfaatkan semaksimal mungkin. Website sekolah yang dikelola dengan baik akan memberikan manfaat yang banyak bagi pihak sekolah, siswa, orang tua dan masyarakat serta mempromosikan sekolah kepada publik yang diakses secara online (Pane \& Sadar, 2015).

\section{DAFTAR PUSTAKA}

Akbar, G., \& Tjendrowaseno, T. I. (2015). Website Profil Sekolah Sebagai Media Informasi Dan Promosi $\mid$ Akbar | IJNS - Indonesian Journal on Networking and Security. https://ijns.org/journal/index.php/ijns/article/view/1316

Anwar, F., Yunianto, M., Purnomo, A., \& Hartono, R. (2017). UPAYA PENINGKATAN KUALITAS SEKOLAH MELALUI PEMBUATAN DAN PENGELOLAAN WEBSITE SEKOLAH Studi Kasus di Sekolah Muhammadiyah se Kecamatan Polokarto Kabupaten Sukoharjo. WASANA NYATA, 1(3), 23-28.

Fanani, F. (2020, September 8). 28 Kabupaten/Kota Ini Berubah Jadi Zona Merah Covid-19. liputan6.com. https://www.liputan6.com/news/read/4351134/28-kabupatenkota-iniberubah-jadi-zona-merah-covid-19

Harminingtyas, R. (2014). Analisis Layanan Website Sebagai Media Promosi, Media Transaksi dan Media Informasi dan Pengaruhnya terhadap Brand Image Perusahaan Pada Hotel Ciputra di Kota Semarang. JURNAL STIE SEMARANG (EDISI ELEKTRONIK), 6(3), 37-57. 
Khusnia, D., \& Riasti, B. K. (2013). Pembuatan Website Profil Sekolah Menengah Pertama Negeri 1 Kalitidu Bojonegoro. IJNS - Indonesian Journal on Networking and Security, 3(1), Article 1. https://doi.org/10.1123/ijns.v3i1.248

Komalasari, R. (2020). Manfaat Teknologi Informasi dan Komunikasi di Masa Pandemi Covid 19. TEMATIK - Jurnal Teknologi Informasi Dan Komunikasi, 7(1), 38-50. https://doi.org/10.38204/tematik.v7i1.369

Marlena, N., \& Sasongko, D. (2012). Pembuatan Website Profil Pada Sekolah Menengah Pertama (SMP) Negeri 2 Kartasura. Speed - Sentra Penelitian Engineering Dan Edukasi, 2(3), Article 3. https://doi.org/10.3112/speed.v2i3.874

mysch.id. (2020). Website Sekolah MySCH.id. https://www.mysch.id/

Nadhira Salsabila. (2020). Perubahan yang Terjadi Dalam Masyarakat Sebagai Dampak dari COVID-19| Fakultas Ilmu Sosial dan Ilmu Politik (FISIP) Universitas Brawijaya. https://fisip.ub.ac.id/?p=10282\&lang=id

Nurmi, N. (2017). Membangun Website Sistem Informasi Dinas Pariwisata. Edik Informatika, 1(2), 1-6. https://doi.org/10.22202/jei.2015.v1i2.1418

Pane, E. S., \& Sadar, M. (2015). Rancangan Website Sistem Informasi Akademik Sekolah Menengah Kejuruan (SMK) Negeri 5 Pekanbaru. Digital Zone: Jurnal Teknologi Informasi Dan Komunikasi, 6(2), 33-41. https://doi.org/10.31849/digitalzone.v6i2.95

Rahadi, D. R. (2007). Peranan teknologi informasi dalam peningkatan pelayanan di sektor publik. Seminar Nasional Teknologi, 2007, 1-13.

Sandy Waradewa. (2020, September 14). Zona Merah, Rencana Belajar Tatap Muka di Madina Batal. Waspada Online. https://waspada.co.id/2020/09/zona-merah-rencanabelajar-tatap-muka-di-madina-batal/

Sikirit, D. (2020). Belajar dari rumah selama pandemi COVID-19. https://www.unicef.org/indonesia/id/coronavirus/cerita/belajar-dari-rumah-selamapandemi-covid-19

Sumartono, S., Huda, N., \& Mardiana, N. (2020). PERSEPSI GURU DAN SISWA TERHADAP KUALITAS, KEPUASAN DAN MANFAAT WEB SMA DHARMA WANITA 4 SIDOARJO. Jurnal Andi Djemma | Jurnal Pendidikan, 3(2), 48-57.

Thorik, S. H. (2020). Efektivitas Pembatasan Sosial Berskala Besar di Indonesia Dalam Penanggulangan Pandemi Covid-19. 'ADALAH, 4(1), Article 1. https://doi.org/10.15408/adalah.v4i1.15506

Utari, R. (2013). WEBSITE SEBAGAI MEDIA HUMAS SEKOLAH. Jurnal Penelitian Ilmu Pendidikan, 6(2), Article 2. https://doi.org/10.21831/jpipfip.v6i2.4800

Utomo, W. B., \& Bakara, C. (2013). Pembuatan Web Profil Sekolah Menengah Pertama Negeri 1 Ngrampal Dengan Menggunakan PHPDan MySQL. Seruni - Seminar Riset Unggulan Nasional Inoformatika Dan Komputer, 2(1), Article 1. https://doi.org/10.0809/seruni.v2i1.711

Wijaya, F., \& Ferdinandus, S. (2020). Pelatihan Pembuatan Dan Pengelolaan WebBlog bagi Guru-Guru Smp Negeri 10 Ambon Sebagai Media Pembelajaran Yang Efektif. JURNAL PENGABDIAN MASYARAKAT JAMAK, 3(1), 217-223. https://doi.org/10.31959/jpmj.v3i1.454

Zaki, A. (2009). Kiat jitu membuat website tanpa modal. Elex Media Komputindo. 